\title{
Tyne and Wear Metro: Bridge N 106 over the River Tyne
}

\author{
P. LAYFIELD, G. TAYLOR, P. McILROY, \\ C. KING \& M. CASEBOURNE
}

\section{Mr C. F. Bonnett, London Transport}

The railway loading in this Paper is based on an equivalent loading which was evolved by London Transport in about 1973, and which has now been incorporated, slightly amended, into the loading section of the revised British Standard 153. This bridge is the first railway bridge in the world of this type of span to be designed to this reduced railway loading, applicable to rapid transit systems.

67. For impact, the allowance appears to be exactly the same as in the revised BS 153 and the London Transport loading. This impact is less than is allowed on railway bridges elsewhere throughout the world and was based on tests which were carried out on certain London Transport bridges. We reduced our impact loading because our stock is somewhat different from main line stock in that it does not have locomotives generally so far as passenger stock is concerned. In the case of Tyne and Wear (Fig. 3), the axle loading for works vehicles is only about $25 \%$ higher than for passenger vehicles. I would like to ask what the operating speeds are and whether any separate calculation was made when determining the impact allowance on static loading.

68. From Fig. 7, which shows the general cross-section of the bridge, the deck units appear to be separate troughs carried on the longitudinal stringers. I would like to ask what precautions were made regarding derailment, because it seems to me that if the diesel locomotive became derailed there could be local instability of the deck units, and that is contrary to what is laid down in the new British Standard. Furthermore, I wonder whether there has been as yet any loading test on the bridge or whether there is any plan for a test loading to prove the actual forces in the members.

69. Although the works loading is more than the passenger loading, I am surprised that none of the elements is subjected to fatigue loading $(\$ 12)$ in that fatigue decides the sizes. I wonder if the Authors could say how many passenger trains are expected to cross the bridge each day. In the light of the sort of frequency that we have in London, I would expect that certainly the stringers and some of the shorter loaded members would be determined by fatigue considerations.

Paper published: Proc. Instn Civ. Engrs, Part 1, 1979, 66, May, 169-189. 
70. In $\$ 19$ there is mention of the individual bearings on the end of the stringers. I quite understand the point that this will completely isolate the deck. I would suggest that in practice this does not matter and that the isolation of individual deck units may have produced a problem relating to waterproofing and joints. I wonder whether the Authors could comment on that. It seems to me that with this detail a transverse joint will be required at each supporting end where there is a sliding bearing of the stringers and that is carrying ballasted track. I would be interested to know how that practical problem has been overcome.

71. London Transport has not used load-indicating washers on its larger structures, largely because of concern about corrosion under the washer and not being able to seal the gaps under the load-indicating washer. I wonder whether the Authors have any comments on that.

\section{Mr B. P. Wex, Freeman Fox \& Partners}

Although Freeman Fox \& Partners are acknowledged here as the independent checkers, I personally had nothing to do with the checking: my comments and questions are raised entirely from my interest as a bridge designer and in no way arise from the work that we did for Fairhurst in relation to the bridge.

73. I would like to congratulate the client, designers and contractors on achieving their bridge at about the estimated price and in about the time. In that connection what problems, if any, did they face with the work force-that is, the erectors - in getting on with the job of erecting the steelwork?

74. Turning to matters of design, I cannot quite understand why the possibility of an arch bridge was ruled out. Obviously, thrust from the arch rib, of whatever form, would be an important consideration. Why not use a tied arch in which the stiffening girder of the bridge forms the tie? This is a not uncommon form, and would have the advantage of conformity with at least one of the other arches on the Tyne. Maybe this was tried and not mentioned, in which case I would be interested to hear what the economic comparisons were.

75. I would like to refer to cable-staying, in steel bridges particularly. About ten years ago $I$ was involved in Bangladesh-East Pakistan, as it then was-in trying to re-girder a bridge, and one of the ideas was to produce a cable-stayed structure in which the mast would assist in dismantling the old bridge as well as erecting the new one. One of the problems was the dynamic response of the cable-stayed configuration to heavy loadings resulting from trains passing. A cable-stayed steel bridge particularly is a fairly flexible structure, and, of course, deflexion response and dynamic response are major considerations, particularly for a railway bridge.

76. There is another point on the configuration concept. The piers are certainly beautiful. But did the Authors consider the use of flexible piers? With tall slender piers encastré at their bases one can dispense with the necessity for complicated bearings on the top and one gets over the expansion and contraction problem simply by allowing the pier itself to flex, giving great simplification in detailing.

77. In the highway bridge field we have departed long since from the concept of multitudinous expansion joints on short panel lengths. We endeavour to get away entirely from these units because they produce maintenance problems at all the joints and bearings. I like a simple life and believe in making all the 
material work: with computer techniques now it is possible to calculate loads for all the members which result if one does not allow any 'breathing' to take place at all. I wonder whether Fairhurst considered making the whole structure locked solid. I would have gone further and suggested that those trough plates that they are using to contain ballast could have been made deliberately stressparticipating. I do not have the fear that I think they have of load-bearing members actually taking rolling loads; that is, field stresses with rolling loads superimposed. I would be interested to hear their comments on that idea.

78. The number of streamlined gusset plates given here is small. As they were used solely for aesthetic reasons, I would like to ask the fabricators if making the curved gusset plates caused them any difficulty and whether they would have preferred to have had the ordinary straight-edged conventional type.

79. I also want to ask about the painting of the box chords. All the box members were of a pretty heavy section, solidly welded together, and yet all ventilated, not sealed at all. I wonder what the thinking was behind that. Why not use fully hermetically sealed box section members?

80. One can see the importance of the flatness of plates for the purpose of grip bolting when very thick plates are used. What sort of gap was there between the thick plates when a member was offered up between the gusset plates? Was the idea considered of trying to get over the problem of match-up by using thin gusset plates, thereby enabling tolerances to be taken up by flexure of the plates, rather than requiring a very close fit-up?

\section{A speaker}

I should be interested to know why a roller bearing was chosen for one of the piers, a sliding plate bearing for the other pier and hemispherical type bearings for the abutments. Why did you not use roller bearings for both piers?

The Chairman, Mr R. N. Sainsbury

The bridge has not yet been subjected to its normal traffic loading, but is its behaviour under longitudinal expansion conforming with what was expected?

\section{Mr K. A. Goodearl, Freeman Fox \& Partners}

The design live load for the bridge is two works ballast trains, whereas the fatigue loading results from passenger trains, which, even when they are full of passengers, give only about $40 \%$ of the loading from the ballast trains. With a span of this order, the dead load stresses are high, so the maximum live load stresses from fully loaded passenger trains of full length will be only about 30 $\mathrm{N} / \mathrm{mm}^{2}$ when two trains are on the bridge, and of the 600 trains a day only a few will be coexistent. I believe that at off-peak periods only two-car trains are run, so the stresses in the truss will be even lower. This means that there are only a few significant loading cycles in the truss.

84. With regard to the stringers, there are no bad fatigue details. There are no welds, just plain plate in the bottom flange of the stringer at mid-span and a bolt hole in the top flange, giving a high fatigue classification. Fig. 3 shows that the ballast trains, which will cross the bridge about once a year, have an intensive loading of four axles of $12 \frac{1}{2} \mathrm{t}$ in a length of about $5 \mathrm{~m}$, compared with the heaviest passenger train loading of two axles of $10 \mathrm{t}$ placed $2 \mathrm{~m}$ apart. Thus in the stringers the fatigue stress level is very rarely significant. 
Mr P. S. A. Berridge, Bridge engineer, formerly with the North Western Railway (India), the GWR and British Rail

This is a valuable paper about the largest steel railway bridge constructed this century. ${ }^{1}$ I would like to know why it was necessary to ballast the tracks on the bridge. I suspect it has been another case of following blindly an age-long British tradition. On N 106, the ballast adds nearly $1000 \mathrm{t}$ of unnecessary dead weight to the structure, the 'trays' and the elaborate waterproofing and tiling add considerably to the quantity of steelwork, and periodical sleeper-packing will add to the cost of maintenance in the future. On Indian railways, it was normal practice to omit ballast on girder bridges; the bridge timbers were hook-bolted directly to the steel. Initially, the timbers were carefully adzed to compensate for the camber of the spans and to give a perfectly level track (Fig. 17); and, apart from some retightening of the hook-bolts during the first few months, no further attention was needed during the 30-40 year life of the timbers.

86. On leaving India and joining the GWR I was told that tracks on bridges were to be ballasted whenever construction depth (the measurement from rail level to bridge soffit) permitted. This was because it was too difficult to maintain a good 'top' to the track at the ends of a ballastless bridge where there was a transition from the rigid steelwork to the comparatively soft formation; it was easier for the permanent-way gang to maintain the track in good alignment if they had a margin in which to slew the track on the bridge; and, in any case, every bridge had to be fully decked to guard against the risk of hot cinders and other droppings falling on people underneath the bridge who might claim against the railway company for the cost of damage to clothing etc.

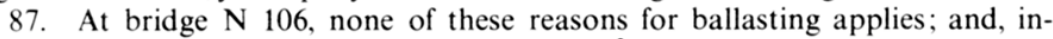
cidentally the Calcutta Rapid Transit System, ${ }^{2}$ which is comparable with the

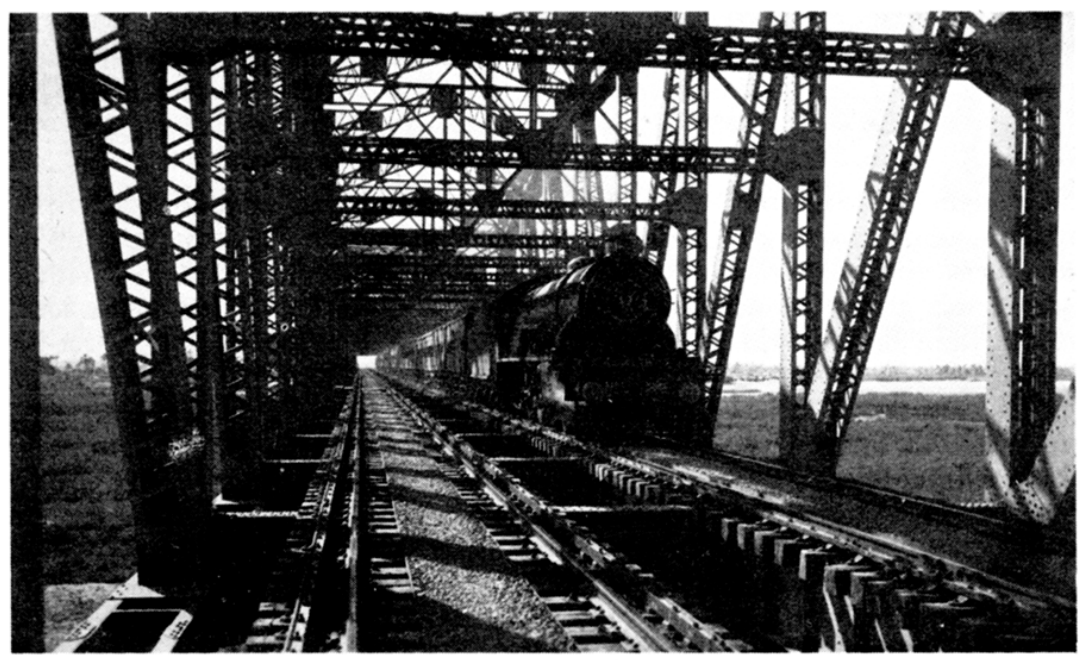

Fig. 17. Perfection in alignment and 'top' attained in ballastless tracks: the KarachiLahore mail train speeding over the Empress Bridge across the river Sutlej in 1944 
Tyne and Wear Metro, is employing ballastless tracks throughout except at points and crossings.

88. My other criticism of $\mathrm{N} 106$ concerns floor interaction. It would add to the interest of the Paper if a longitudinal section could be given showing how the stringers are supported at their 'free' ends, and how the rails span over the cross-girders from 'tray' to 'tray'. Floor interaction ${ }^{3}$ appears to have been interrupted $(\S 19)$ so far as the rail-bearers are concerned; but, has the deformation stressing of the lateral bracing been considered? Practical experience in India and the UK has shown that considerable economy can be achieved by making the floor girderwork interact with the main trusses. Indeed, a number of elderly girder bridges have been strengthened by alteration of the stringers to make them continuous from end to end of the span and providing additional deck steelwork to transfer the horizontal shear stresses to the main girderwork at the panels adjacent to the bearings. Such continuity designed to give complete interaction between stringers, lateral bracing and main trusses has the following advantages:

(a) objectionable eccentric loading of cross-girders, unavoidable where the 'free' ends of stringers bear on short brackets, is eliminated;

(b) with top flange connections of the stringers oversailing the cross-girders and the lower flanges connected through windows cut in the webs of the cross-girders, the continuous girder stringers require less steel than they would as simply supported girders;

(c) the absence of moving parts simplifies future maintenance.

Moreover, the high strength friction grip bolt can take direct tension in the shank whereas the hot-driven rivet of pre-welding days invariably worked loose if the shank was subjected to direct tension.

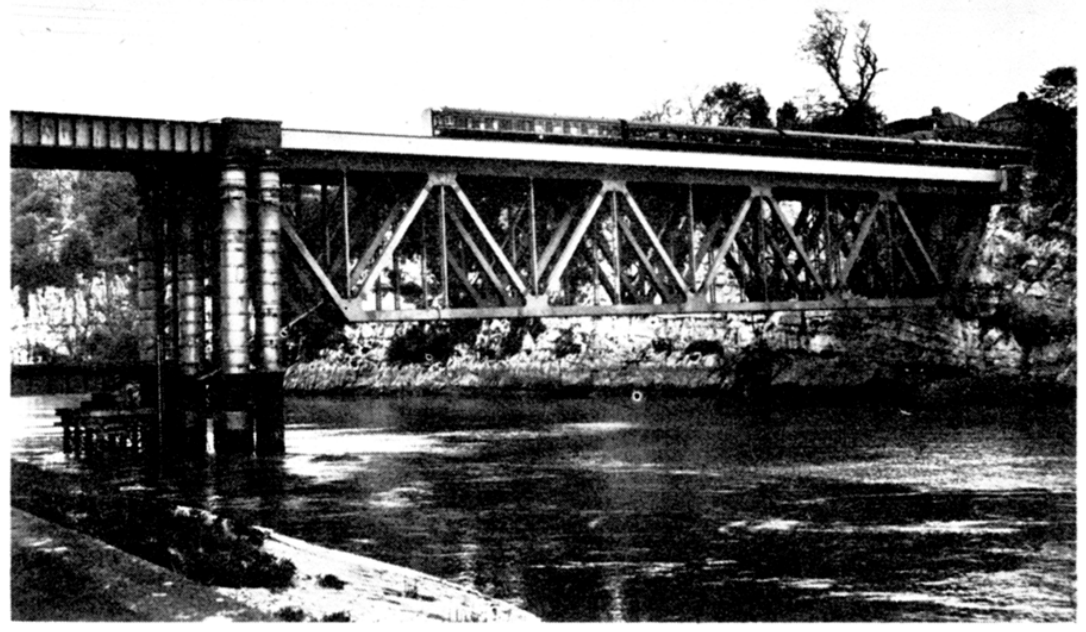

Fig. 18. British Rail's bridge across the river Wye at Chepstow, showing the welded trussed-box girders in which the deck system is incorporated with the trusses 


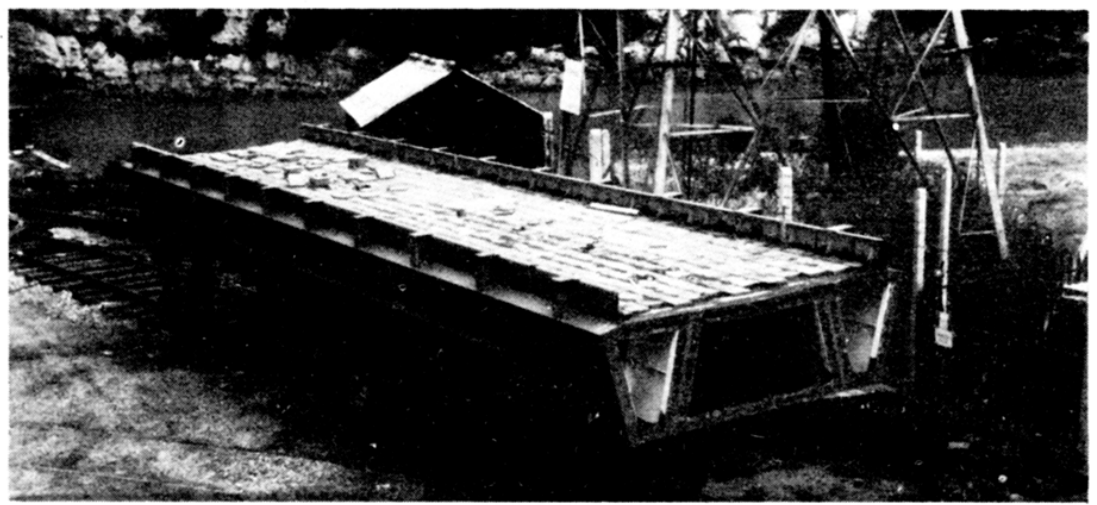

Fig. 19. Fabricated completely in the workshops, waterproofed and tiled ready to be ballasted immediately after erection, a $60 \mathrm{ft}$ long section of the top chord of one of the spans for Chepstow Bridge en route to the site

89. Full advantage of floor interaction was taken in the design of British Rail's trussed box girders used in the $308 \mathrm{ft}$ long spans of the Wye Bridge at Chepstow in 1962 (Fig. 18). Designed to carry the heaviest mainline loading at unrestricted speed, these spans embody steelwork averaging only 0.97 tons per linear foot of track; and, that is in spite of the tracks being ballasted (Fig. 19). It is significant that all the hollow box-section web members were left unpainted on the inside surfaces and they were rendered air-tight by welding when being fabricated. This being contrary to the ventilated interiors in the $\mathrm{N} 106$ trusses $(\S 35)$, it will be interesting to compare the future behaviour of the chords over the Tyne with that of the box-section web members in the Chepstow Bridge.

Mr K. J. Thomas, PSA, Central Office for Wales

I am interested in the Authors' comments on the use of HSFG bolts in $\S 28$, and the application of the information to other structures. Do the Authors have any information on the area over which the clamping force needs to be spread as shown by the testing? Did the tests show a maximum permitted distortion that could be removed by bolt tensioning? The possibility of pulling distorted plates into contact is presumably related to the plate thickness. What size and thickness of plates were used at the quoted tolerance of $\pm 0.6 \mathrm{~mm}$ and how was this tolerance achieved in fabrication? Do the Authors consider that this close tolerance could have been relaxed as a result of their experience in the actual assembly?

\section{Mr D. E. Sinclair, Member}

The concept of a finite length of train on a long span bridge is an interesting innovation, though, in practice, there cannot be many railway bridges with a continuous construction in excess of typical train lengths.

92. Perhaps the Authors could indicate what factors lead to the choice of ballasted track with its possible attendant difficulties in maintaining line and level, rather than, say, wheeltimbers (waybeams) or a concrete slab deck, 
possibly acting compositely with the longitudinal rail bearers with the rails mounted on pads or baseplates.

93. It is good to learn that thought was given to the future maintenance of the bridge, so that equipment has been provided as part and parcel of the bridge and will not have to be devised at some future date when it is required. No mention is made about means of access above rail level; could the Authors say how it is envisiaged that the outside and inside faces of the trusses will be reached. Is there any provision along the length of the bridge of energy take-off points (e.g., electricity, compressed air) for use during future maintenance?

\section{Mr Layfield, Mr Taylor, Mr Mcllroy, Mr King and Mr Casebourne}

In reply to Mr Bonnett, the characteristic speeds taken for design purposes were $50 \mathrm{~km} / \mathrm{h}$ for works trains and $80 \mathrm{~km} / \mathrm{h}$ for passenger trains. A section of the design live loading specification devised for Tyne and Wear Metro deals with derailment forces; the general principle is that railway bridges shall be so designed that they do not suffer excessive damage or become unstable in the event of a derailment. The deck units are designed, therefore, in such a way that while they can suffer distortion or slight displacement in the event of the derailment of a deisel locomotive, this would not be catastrophic. Furthermore, the design allows for the comparatively simple removal and replacement of a deck unit without causing major disruption.

95. The placing of the ballast was used as an opportunity to monitor the behaviour of the structure as loads were added to it; behaviour was as predicted and no further load tests are contemplated.

96. The highest frequency of passenger trains likely to cross the bridge is 600 per day. As suggested by Mr Bonnett, joint waterproofing was installed at each transverse joint between deck units. The design of the joint was uncomplicated, comprising a 'top-hat' arrangement of waterproofing material protected by a steel plate to prevent damage from ballast. The deck plates are drained at fairly frequent intervals with plastic pipes carrying water to below stringer level. After more than twelve months in service, the waterproofing appears to be effective.

97. Care has been taken to seal the load-indicating washers before painting. Experience elsewhere has given the designers confidence in the use of properly sealed load-indicating washers.

98. In reply to Mr Wex, there was, happily, almost no problem with the steel erectors working on the project. Many of them had experience of big bridge erection; the erection procedure was virtually designed into the bridge from the outset and was reasonably straightforward.

99. A tied arch bridge was considered. Its span would have been considerably greater than that of the existing Tyne Bridge and the designers felt that it would have been unduly dominant in the river scene. It would also have been much more expensive.

100. The use of flexible piers was considered and might well have been appropriate for the south pier. However, the north river pier was founded on $\mathrm{H}$ piles through fairly deep river deposits into rock at a low level, and on balance it was thought better to provide rolling and sliding bearings on the piers. The roller bearing was much more expensive than the sliding bearing and for this reason it was used only on the north river pier, where the thermal movements are expected to be much greater than on the south river pier. 
101. The idea of a solid deck was considered but it was thought on balance better to build in the long term advantage of easy replacement of deck units, and at the same time avoid the complex stress conditions which would occur in a solid deck due to deflexions of the trusses during the passage of heavy loads.

102. The production of curved gusset plates created no difficulty to the fabricator and, in fact, saved some weight of steel. The decision to ventilate the box chords was taken in the light of experience elsewhere of the extreme difficulty of guaranteeing sealing. The boxes and their diaphragms are large enough and accessible enough to permit regular inspection and touching up where necessary.

103. Allowance was made in the design for $10 \mathrm{~mm}$ gaps between the gusset plates in the box chords and the vertical and diagonal members of the trusses. Packing pieces of this thickness were used in all but one or two cases where specially machined packs were permitted to overcome a slight out-of-tolerance. The use of thin gusset plates was not considered, as one of the objectives of the design of the box chords was to keep them streamlined in appearance. The behaviour of bolts on fairly thick plates was studied carefully at Bristol University on behalf of the designers in order to assess the importance or otherwise of the flatness of the plate.

104. In reply to Mr Sainsbury, the behaviour of the bridge under longitudinal expansion has been monitored carefully ever since it joined at the centre of the river in July 1978. Its behaviour is as expected.

105. We are grateful to Mr Goodearl for his comments on fatigue loading; $\mathrm{Mr}$ Goodearl was largely responsible for the independent design check on behalf of Freeman Fox \& Partners.

106. We do not claim that bridge N 106 is the largest steel railway bridge constructed this century; it is, however, probably the longest continuous truss bearing continuous welded railtrack. In reply to Mr Berridge, the use of timber waybeams was considered, as was the use of a continuous concrete deck, but both were rejected in favour of a ballasted track for a number of reasons:

(a) with a railway bridge of this very long central span it is desirable to keep the live load to a small proportion of the dead load in order to minimize distortions and deflexions;

(b) the use of ballast allows some flexibility in the setting out of the track;

(c) the use of ballast enabled the designers to keep the continuous welded track entirely free of the forces which would otherwise have been transmitted into the track during the 'breathing' movements of the deck units during the passage of a train;

(d) at the time the decision was made it was expected by the Passenger Transport Executive that much of the adjoining track would be ballasted.

The use of the continuous deck with continuous stringers might possibly have shown some economy but we would not have been happy to combine this with continuous welded rail, even with ballast. The most important consideration is a smooth ride for the passengers.

107. In reply to Mr Thomas, the extensive testing programme on the $30 \mathrm{~mm}$ dia. HSFG bolts at Bristol University showed that the contact area of the faying surfaces was less important than the condition of the faying surfaces. The testing programme included tests on deliberately distorted plates. The gusset plates 
which were incorporated in the webs of the top and bottom chords varied in thickness up to $50 \mathrm{~mm}$. The original flatness tolerance was modified to $\pm 0.6 \mathrm{~mm}$ on a $600 \mathrm{~mm}$ straight edge, which was achieved in most cases by the Contractor; where the flatness was found to be out of tolerance a review was made jointly by the Contractor and the designers and in some cases a few additional bolts were provided to compensate for the resulting lack of efficiency in the connection. If this design were to be repeated, Fairhurst would not relax this degree of tolerance.

108. In reply to $\mathbf{M r}$ Sinclair, maintenance work and painting above rail level can readily be carried out from cradles strung from the top chords and $\mathrm{K}$ bracing; however, work directly above and within $2 \mathrm{~m}$ of the overhead line equipment will have to take place during periods when power is disconnected, requiring careful co-ordination by the Executive. No specific provision has been made at this stage for any maintenance electricity or compressed air supply but there is room in the cable ducts or along the parapets for such services to be provided when they become necessary.

\section{References}

1. New Civil Engineer, 1977, 26 Aug.

2. Dasgupta K. N. et al. The Calcutta Rapid Transit System and the Park Street underground station. Proc. Instn Civ. Engrs, Part 1, 1979, 66, May, 261-275.

3. REMFrey D. H. The interaction in bridgework of the deck system on the main girders, and the consequent modification of stresses therein. Min. Proc. Instn Civ. Engrs, $1923-24,218,181-224$. 